\title{
Measuring System for Pressure Sensitive Paint (PSP) Calibration in the Range of Low Pressure Gains
}

\author{
Michał Strozik ${ }^{1}$, Mirosław Majkut ${ }^{1} \&$ Sławomir Dykas $^{1}$ \\ ${ }^{1}$ Silesian University of Technology, Institute of Power Engineering and Turbomachinery, Gliwice, Poland \\ Correspondence: Michał Strozik, Silesian University of Technology, ul. Konarskiego 18, 44-100 Gliwice, Poland \\ Tel: 48-32-237-1239. E-mail: michal.strozik@polsl.pl
}

Received: July 17, 2014

doi:10.5539/mas.v9n2p116
Accepted: August 3, $2014 \quad$ Online Published: January 10, 2015

URL: http://dx.doi.org/10.5539/mas.v9n2p116

\begin{abstract}
The measurement by means of the PSP method in the range of low pressure gains (up to $\pm 30 \mathrm{kPa}$ ) may constitute a supplement to the low-pressure compressor stage research methods (pitot tubes, thermal anemometry, LDA). This paper presents an in-house PSP calibration system implemented in the Institute of Power Engineering and Turbomachinery of the Silesian University of Technology. The tests were carried out using a calibration chamber co-operating with a measuring system controlled by an original handler operating in the LabView environment. The pressure-dependent luminous intensity of recorded light was determined at different values of temperature and levels of excitation illumination. The system makes it possible to calibrate pressure sensitive paints and perform measurements in the range of pressure values occurring in the systems of industrial fans.
\end{abstract}

Keywords: pressure sensitive paint, experiment, low-pressure compressor stage, luminous intensity

\section{Introduction}

Research on pressure and temperature sensitive paints has been conducted since 1980. The PSP technique allows a quantitative visualization of film pressure and provides information on flow structures that cannot be determined using conventional pressure gauges. The PSP research method is based on the phenomenon of changes in the intensity of fluorescent radiation emitted by paint. It draws on the phenomenon of what is referred to as thermal/ oxygen quenching, which is a reversible process of molecular photoluminescence. Paint particles illuminated by an appropriate light source can emit light and react with oxygen particles, losing energy in the process (luminescence quenching). A part of this lost energy is directly proportional to oxygen concentration and mobility in the polymer layer. The luminescence effect is inversely proportional to the partial pressure of oxygen over the polymer surface. If oxygen concentration in air is constant, the luminescence quenching effect can be used to measure air pressure. Individual energy levels and photophysical parameters of the luminescence process for a simple luminophore were described by Jabłoński [Gregory et al, 2008]. According to Henry's law, oxygen concentration in a PSP polymer is proportional to the oxygen partial pressure. The conclusion is that luminescence intensity decreases as pressure rises. The relationship between luminescence intensity and oxygen concentration is also described by the Stern-Volmer equation [H.Sakaue et al, 2001].

$$
\frac{I_{\text {ref }}}{I}=A+B \frac{p}{p_{\text {ref }}}
$$

I $\quad-$ luminescence intensity

$p \quad-$ air pressure

$I_{\text {ref }}, p_{\text {ref }}-$ reference conditions

$A$, $B \quad$ - temperature-dependent coefficients

Typically, the $\mathrm{I}_{\mathrm{ref}} / \mathrm{I}$ intensity ratio is determined in the measurements, which eliminates the impact of the PSP luminophore non-uniform illumination and inhomogeneous concentration. In typical wind tunnel tests, the reference conditions $\mathrm{I}_{\mathrm{ref}}$ and $\mathrm{p}_{\mathrm{ref}}$ are assumed as those prevailing when the tunnel is not active.

Pressure can be calculated from the Stern-Volmer equation directly. In practice, however, the CCD camera image does not always coincide with the reference image. PSP's are sensitive to changes in temperature, which is 
another source of the measuring error. Therefore, proper measurements are always preceded by paint calibration. The calibration consists in determining, for different temperatures, the value of the intensity ratio depending on pressure for the tested layer of the PSP. In order to reduce the measuring error, additional data processing procedures are used.

The most difficult area for the use of PSP's are measurements in low-speed aerodynamics [Bell, 2004]. The pressure sensitivity of standard PSP preparations ranges from 600 to 1200 Pa per $1 \%$ of changes in intensity, and their temperature sensitivity is about 600 to $1000 \mathrm{~Pa}$ per one degree Celsius. For objects moving with the speed of $50 \mathrm{~m} / \mathrm{s}$, the pressure on their surface is of the order of $1500 \mathrm{~Pa}$. This requires an image detector with a high dynamics and accuracy of the light intensity measurement, a precise determination of the paint temperature and stability of the excitation light emitter. The model deformations and shifting in the position to the light source cause additional problems.

\section{PSP's and the Calibration System}

The cost of purchase of a laboratory system of measurement by means of the PSP method is very high and the PSP calibration data made available by manufacturers can usually be used only with the instrumentation made by them [Liu et al, 2001].

Within the works of [project, 2011], an in-house measuring system for PSP calibration and testing was designed and implemented (Fig. 1). PSP calibration is carried out using a calibration chamber. On the side of the CCD camera and the excitation emitter, the chamber has a $\Phi=175 \mathrm{~mm}$ window made of quartz glass. On the rear cover, where the plate with a PSP layer is fixed, a double stack of Peltier modules is installed with the dimensions of $62 \times 62 \mathrm{~mm}$ and total power of $520 \mathrm{~W}$. Heat is extracted from the stack by a cooling fan system cooled with heat-pipes or, alternatively, with water. The Peltier system, combined with a ColTronic TC2812 PID controller, makes it possible to set temperatures in the range of $10^{\circ} \div 50^{\circ} \mathrm{C}$ with a $0.1^{\circ} \mathrm{C}$ accuracy. Temperature is measured by a three-point system of miniature Pt100 sensors located under the plate covered with a PSP layer. The maximum dimensions of the plates are $70 \mathrm{x} 90 \mathrm{~mm}$. A computer-controlled pressure calibrator controls the system setting pressure in the range of $10 \div 200 \mathrm{kPa}$. Owing to the DPI 620 multifunction calibrator made by the GE Sensing company, it is possible to make a precise pressure measurement (accuracy class 0.015). Excitation illumination is provided by a $20 \mathrm{~W}$ array of UV $400 \mathrm{~nm}$ LED's. During the calibration, the spectrum of the luminescence emission is analyzed additionally using a fibre-optic spectrophotometer. The image recording system is ensured by a DFK 23FM021 industrial camera with a 1280x960 pixel matrix and a 12-bit dynamic range in the grey scale. A band filter with a spectral range of $650 \pm 50 \mathrm{~nm}$ is mounted on the lens, which allows recording the principal emission mode of the PSP luminescence and a preliminary filtering of parasitic light effects related to the illumination background.

All the measurement system subsystems are connected to a PC-type computer. The measurement is controlled and the results are logged by means of the PSPCal program made by the Authors. The program operates in the LabView environment. The basic functions of the program are as follows: finding the PSP calibration curves, measurement and logging of the measurement parameters, camera image recording, image analysis and determination of intensity ratios, data averaging for selected areas of the CCD matrix. The program allows automatic paint calibration according to a programmed algorithm. The only data that need to be specified are the range and the number of points of set pressure and temperature values. The program main menu is shown in Fig. 2a. The measuring data are processed in the "Calibration File Creation Module". The results are displayed as numeric data or interpolated charts (Fig. 3c) The calibration data are then normalized to reference conditions and stored in calibration files in the form of the intensity ratio or the $\mathrm{p} / \mathrm{p}_{\text {ref }}$ quotient values (Fig. $3 \mathrm{~d}$ ). The program uses calibration files created in this way to determine pressure values based on recorded images. It also makes it possible for the user to check the calibration results by entering own data. A separate component of the program is the "Pressure Measurement Module". It is used to measure pressure on tested surfaces based on the measurement and reference images recorded by the CCD camera. The calculations are run in a 16-bit scale of intensity. It is possible to select for the analysis the entire area of the recorded image (CCD camera full resolution) or a fragment of the photograph only (Fig. 2a). 

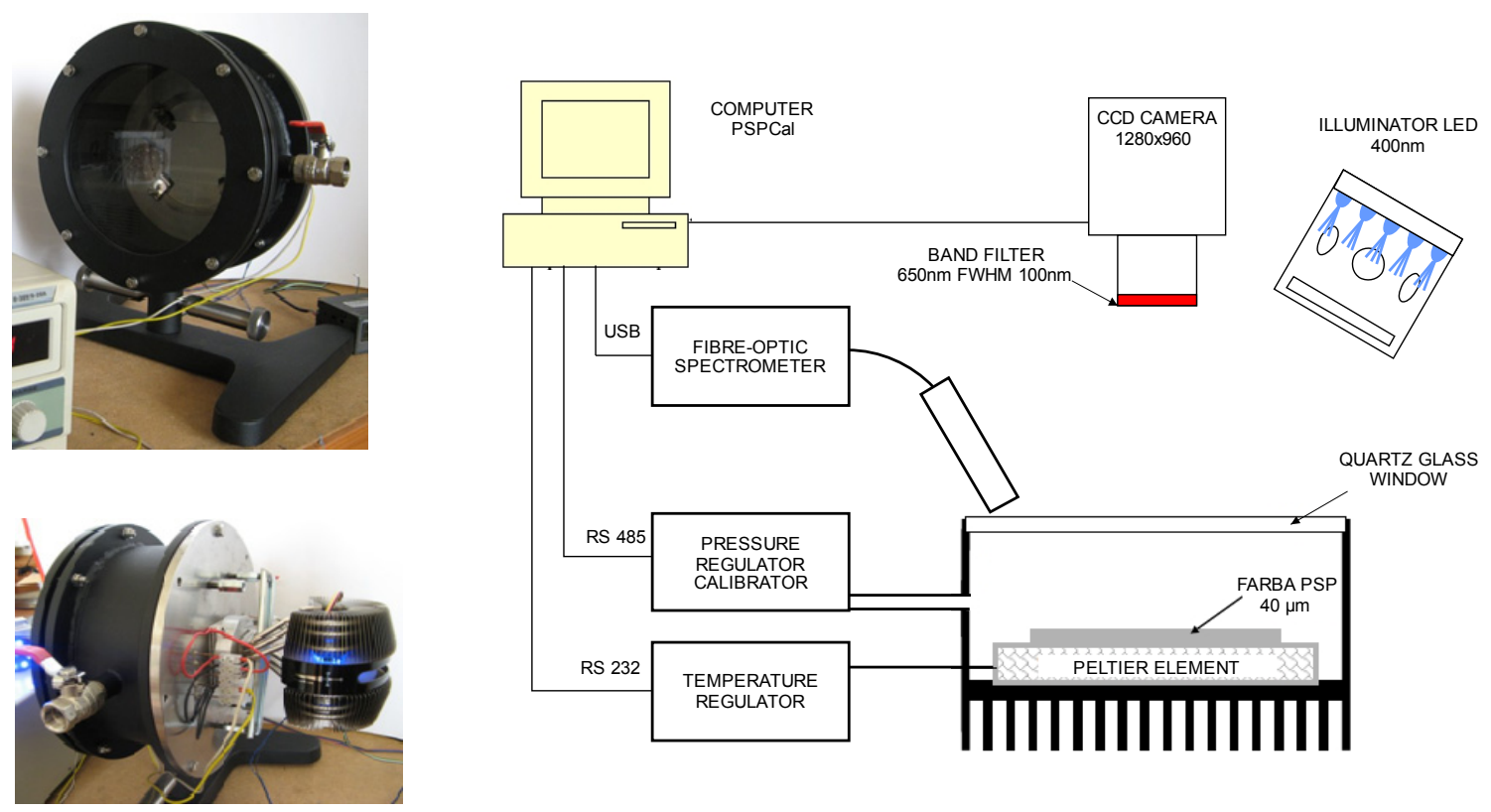

Figure 1. Calibration chamber and diagram of the PSP calibration system

a)

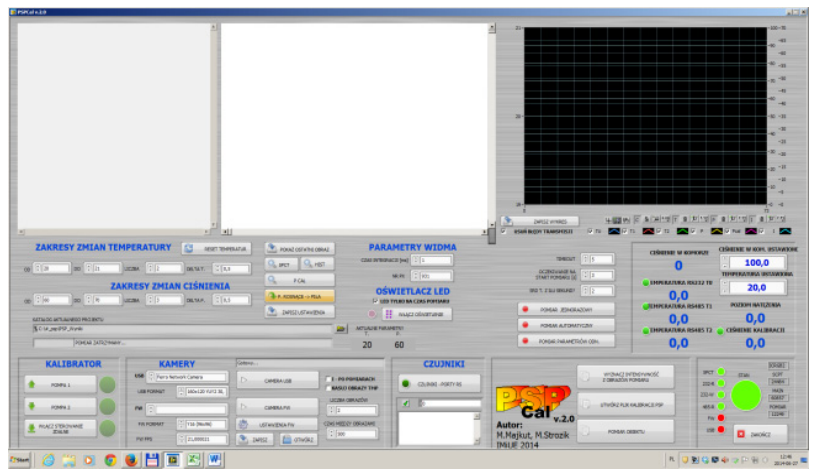

c)

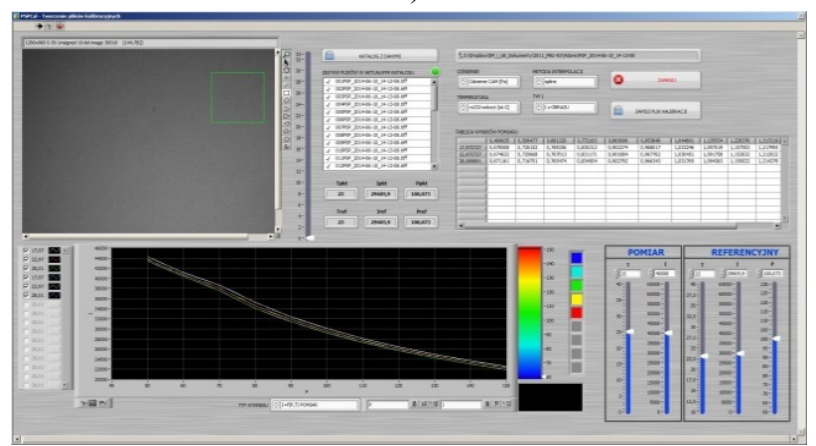

b)

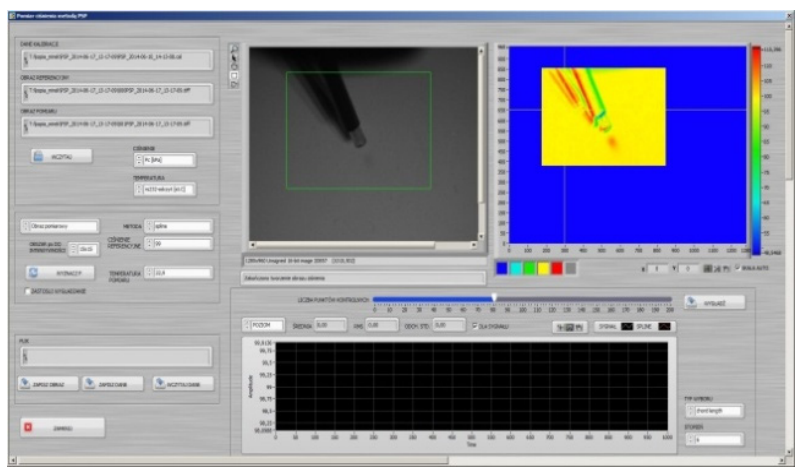

d)

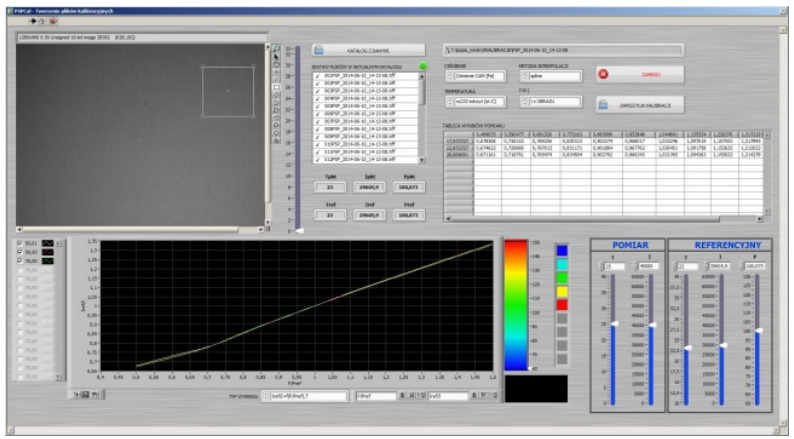

Figure 2. PSPCal program screen dumps: a) main menu, b) measuring menu, c) and d) calibration menu

All obtained results and images are logged and recorded, which makes it possible to enter them into the program later to run an additional post-processing sequence. 


\section{PSP Calibration}

The testing stand described above was used to test the ISSI pressure sensitive paints: UniFIB (UF400) and TurboFIB (TF200) [Bell, 2004]. These paints are characterized by a different time of response to changes in pressure $-750 \mathrm{~ms}$ and $1 \mathrm{~ms}$, respectively. The paint selection was conditioned by the needs of the planned target measurements in a low-pressure compressor stage. Because pressure gains occurring in fans are slight, of the order of $\pm 30 \mathrm{kPa}$, and because temperatures vary in the range of $10 \div 50^{\circ} \mathrm{C}$, tests were limited to these values only.

a)

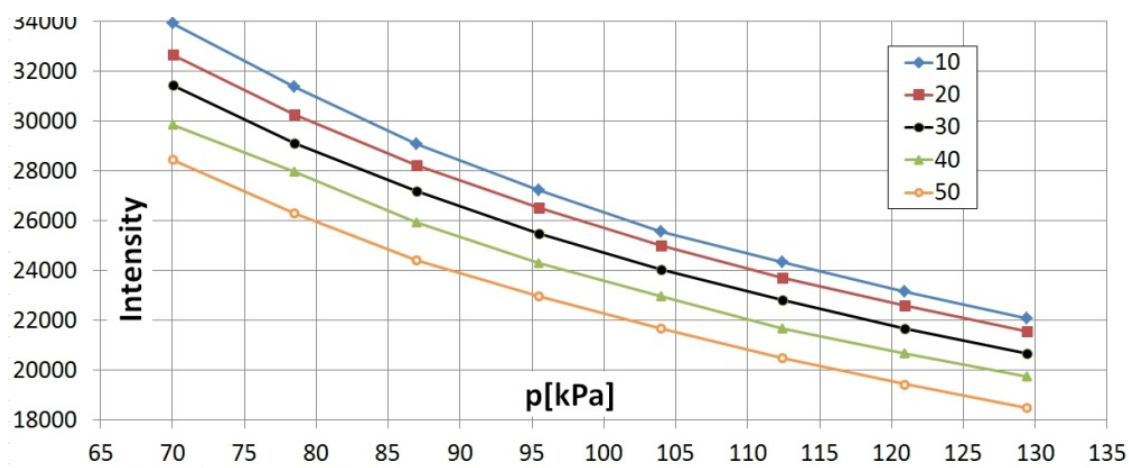

b)

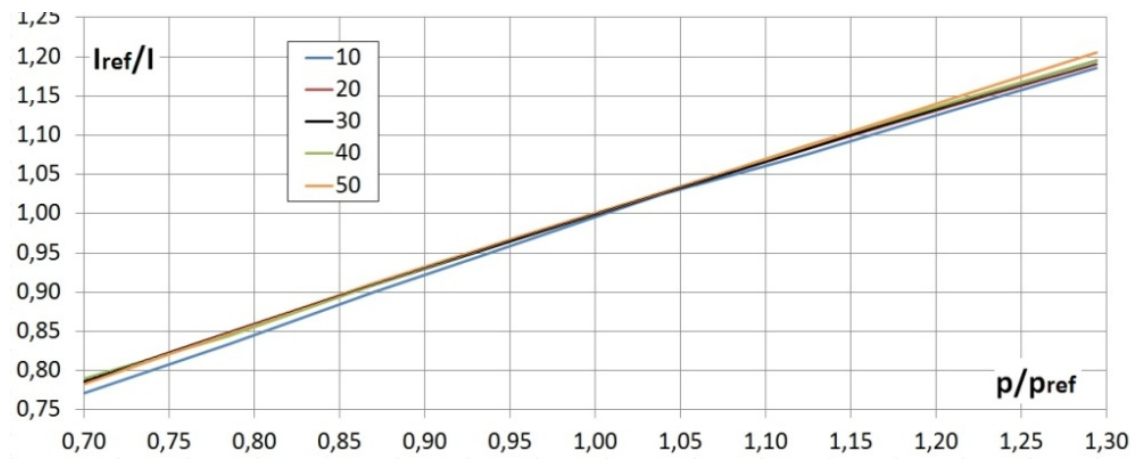

c)

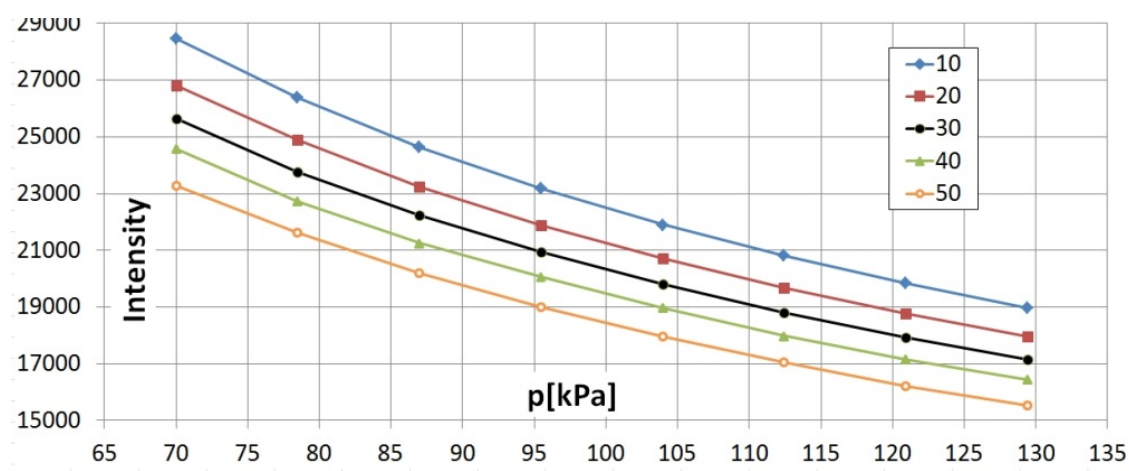

d)

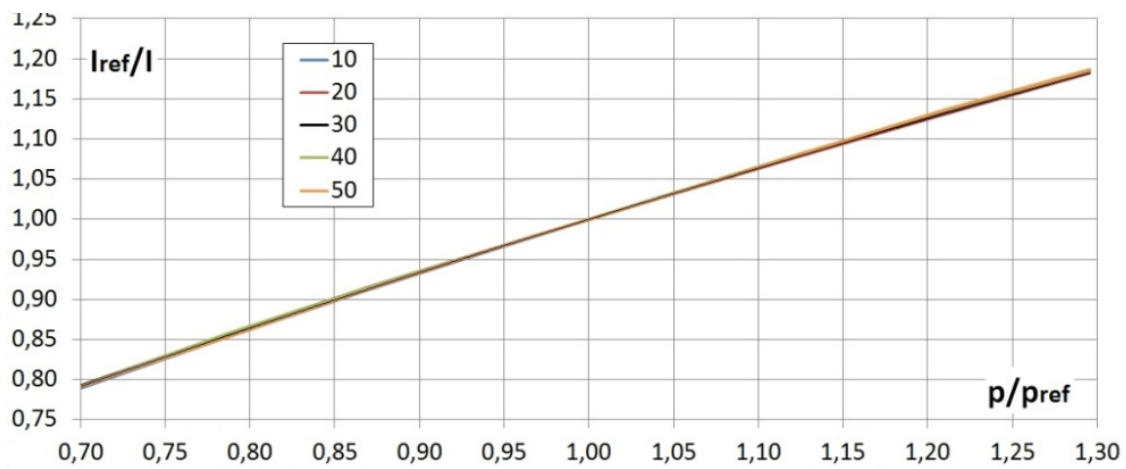

Figure 3. Calibration curves: a), b) UniFIB (UF-400), c), d) TurboFIB (TF-200) 
In the first stage of the testing, metrological parameters of the constructed measuring system were identified, the operation of the calibration chamber with its instrumentation was checked and the properties of the CCD camera were determined. Thermal tests of paint-coated plates were performed (heating and cooling) and the Peltier module PID temperature controller parameters were determined. The temperature field uniformity on the analyzed surface was examined using a thermal imaging camera. Example results of the measurement of the temperature field on the analyzed plate surface are shown in Fig. 5b. The recorded non-uniformity of the temperature field did not exceed $0.2^{\circ} \mathrm{C}$. The calibration chamber pressure stabilization and control system was also checked. Two CCD cameras and several versions of UV emitters were tested in terms of the stability of parameters and the quality of the recorded image. The prepared system handler was tested for different configurations of equipment and varied operating parameters.

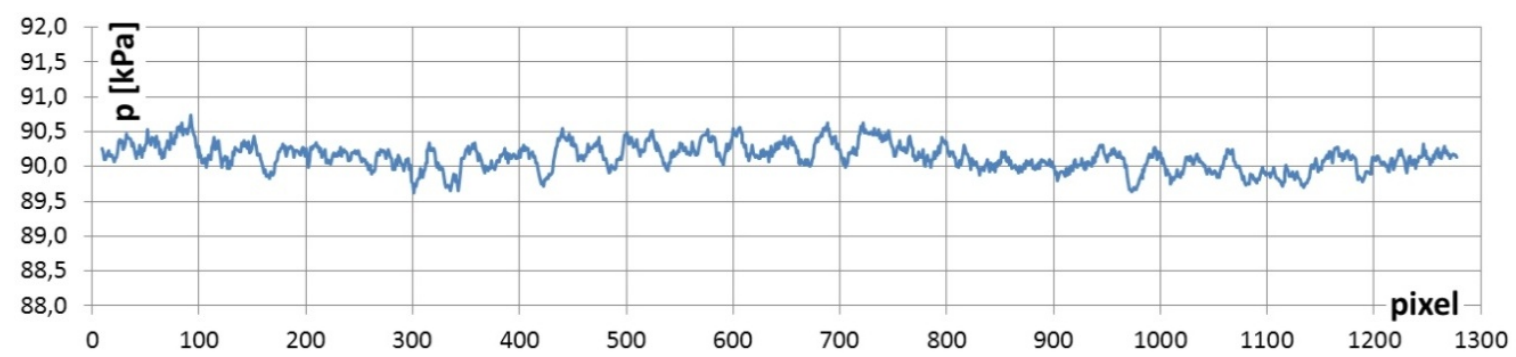

a) line $\mathrm{X}, \mathrm{p}_{\mathrm{z} 1}=90.13 \mathrm{kPa}, \mathrm{t}=23^{\circ} \mathrm{C}, \mathrm{P}_{\mathrm{XRMS}}=90.25 \mathrm{kPa}, \delta=0.17$

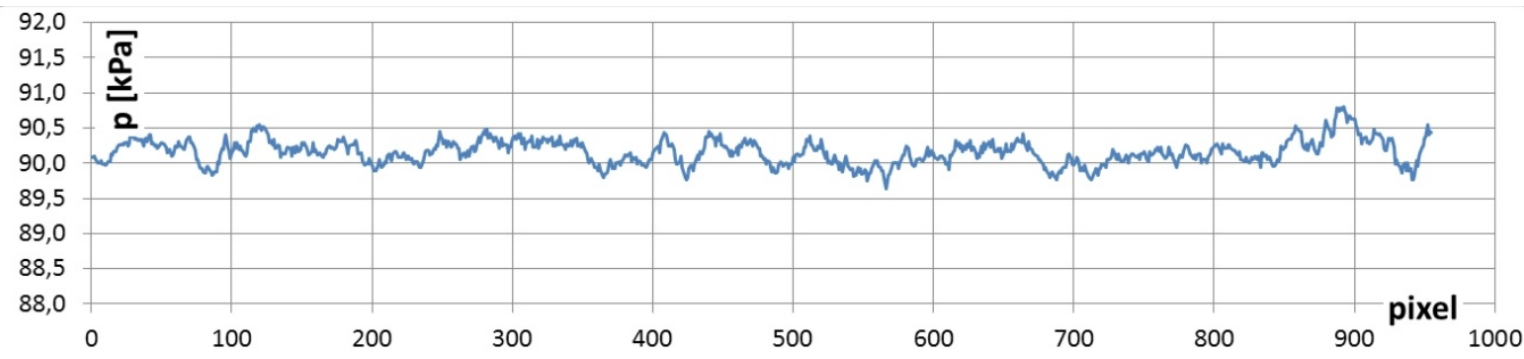

b) line $\mathrm{Y} \mathrm{p}_{\mathrm{z} 1}=90.13 \mathrm{kPa}, \mathrm{t}=23^{\circ} \mathrm{C}, \mathrm{P}_{\mathrm{YRMS}}=90.16 \mathrm{kPa}, \delta=0.17$

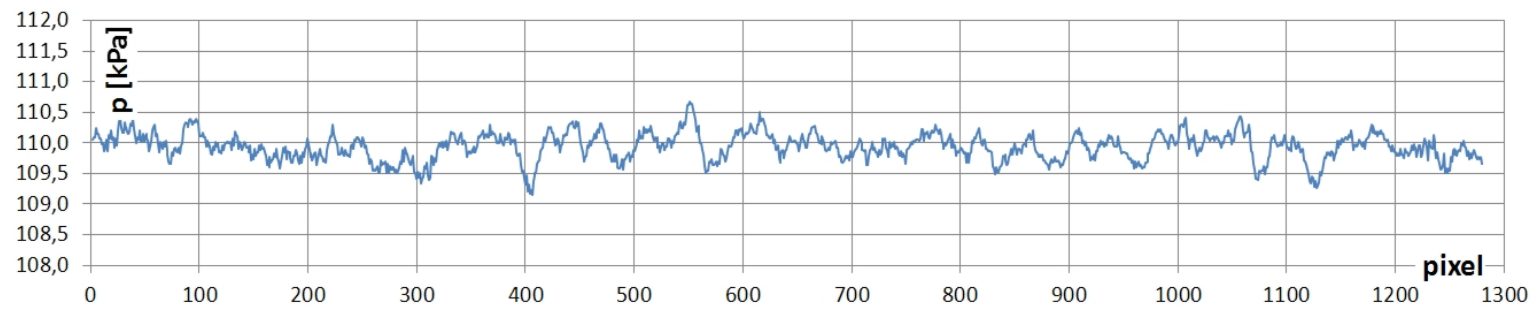

c) line $\mathrm{X}, \mathrm{p}_{\mathrm{z} 2}=109.83 \mathrm{kPa}, \mathrm{t}=23^{\circ} \mathrm{C}, \mathrm{P}_{\mathrm{XRMS}}=109.96 \mathrm{kPa}, \delta=0.23$

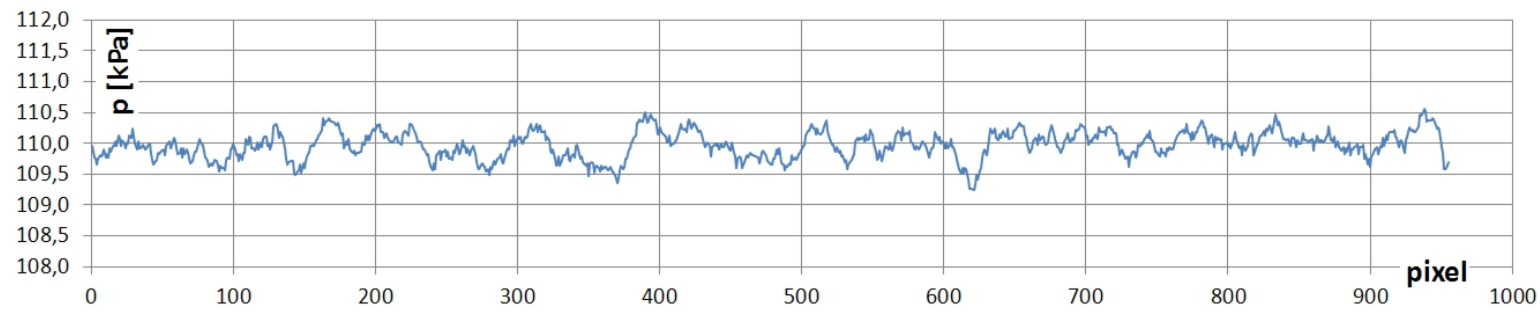

d) line $\mathrm{Y} \mathrm{p} \mathrm{p}_{\mathrm{z} 2}=109.83 \mathrm{kPa}, \mathrm{t}=23^{\circ} \mathrm{C}, \mathrm{P}_{\mathrm{YRMS}}=109.98 \mathrm{kPa}, \delta=0.22$

Figure 4. Control measurements for the UniFIB PSP

The effects of the automatic calibration process are calibration data files and sets of curves generated in the PSPCal program. Fig. 3 presents calibration curves found for the PSP's under analysis. In the case of the UniFIB paint with an average layer thickness of $42 \mu \mathrm{m}$, the calibration was carried out in the $70 \div 130 \mathrm{kPa}$ range of 
changes in pressure and for the temperature range of $10 \div 50^{\circ} \mathrm{C}$. Fig. 3a illustrates the dependence of luminescence intensity depending on pressure for three values of temperature. Based on the measured values (marked on the chart with points), the spline method was used to find the interpolation equations of the calibration curves (solid lines). After normalization to reference parameters, a pencil of curves is obtained passing through the point $(1,1)$ and corresponding to reference conditions (Fig $3 b$ ). The curves practically coincide, which proves that the impact of temperature on the paint properties is slight. Changes in the Iref/I intensity ratio were found. They amounted to approximately $0.5 \% /{ }^{\circ} \mathrm{C}$ for the UniFIB paint and $0.3 \% /{ }^{\circ} \mathrm{C}$ for the UniFIB paint. This conforms with the paint manufacturer's data. In the process of pressure determination, the program uses equations describing calibration curves, taking account of the appropriate temperature correction of the intensity ratio. The intensity found from the measuring process is a mean value from the $15 \times 15$ pixel fragment of the CCD camera image, which corresponds to geometrical dimensions of $0.6 \times 0.6 \mathrm{~mm}$ of the analyzed area. The averaging makes it possible to improve the signal/noise ratio during the light intensity measurement and eliminate the impact of the paint layer thickness non-uniformity on the surface under analysis. The program allows averaging selection in the range from $1 \times 1$ to $99 x 99$ pixels. Fig. $3 \mathrm{c}$ presents the TurboFIB paint calibration results.

In order to verify the calibration procedure, control measurements were performed. For this purpose, the pressure field on the surface of the PSP-covered plate was determined for different pressure levels set in the calibration chamber $\left(\mathrm{p}_{\mathrm{z} 1}=90.13 \mathrm{kPa}, \mathrm{p}_{\mathrm{z} 2}=109.83 \mathrm{kPa}\right)$. Example results of measurements for the UniFIB paint are presented in Fig. 4. The charts show pressure distributions on areas selected from the middle parts of lines $\mathrm{X}$ and $\mathrm{Y}$, which are perpendicular to each other. Root mean square pressure values along the lines $\left(\mathrm{P}_{\mathrm{XRMS}}=9025 \mathrm{kPa}, \mathrm{P}_{\mathrm{YRMS}}=90.16 \mathrm{kPa}\right)$ and standard deviations of the measurement of 0.16 and 0.23 for line $\mathrm{X}$ and $\mathrm{Y}$, respectively, were found. This gives measuring uncertainty at the level of $0.2 \%$. The results were obtained at a $15 \times 15$ pixel averaging area. The impact of the averaging area size on the standard deviation value was also examined. Fig. 5a presents results of pressure measurements along line $\mathrm{X}$ averaged in the $7 \times 7$ to $31 \times 31$ pixel areas. This corresponds to square measuring areas with $0.3,0.6$ and $1.2 \mathrm{~mm}$ long sides, respectively. The $15 \times 15$ pixel measuring area was assumed for further measurements. The standard deviation in this case is $\delta=0.23$. This gives a laboratory accuracy class of the measurement.

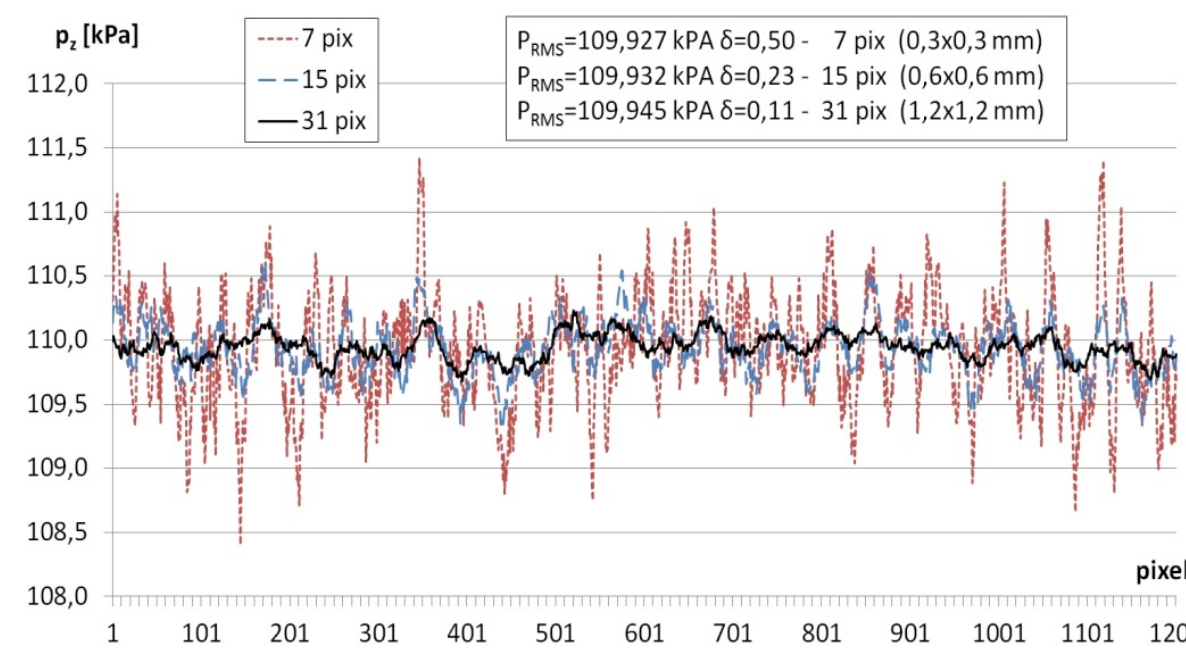

a)

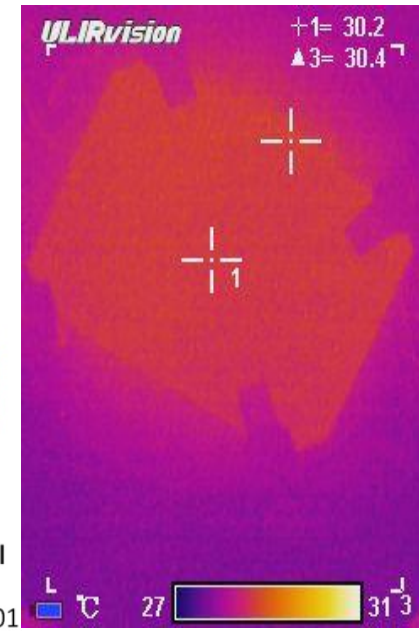

b)

Figure 5. a) Averaging results for different dimensions for the UniFIB PSP; line $X, p_{z 2}=109.83 \mathrm{kPa}, \mathrm{t}=23^{\circ} \mathrm{C} \quad$ b) Temperature field measurement

\section{Conclusions}

The presented research method with the use of pressure sensitive paints (PSP's) will be a supplement to research techniques used in the Fan Laboratory of the Institute of Power Engineering and Turbomachinery of the Silesian University of Technology. So far, experimental works have been performed on the low-speed compression stage testing stand using measurement systems which operate based on different physical principles and which are listed below: 
- a measuring system using aerodynamic probes for the testing of an averaged flow [Witkowski et all, 1996].

- $\quad$ contact measuring system using triple-split film probes (TSFP's) [Witkowski et all, 2004, 2005].

- $\quad$ non-contact system using a three-dimensional laser Doppler anemometer (3-D LDA) [Witkowski et all, 2003, 2008].

- $\quad$ a system of 32 high-frequency pressure transducers arranged on the rotor wheel outer cover to test pressure in the tip clearance.

The first three testing methods are used to determine velocity fields, which makes it possible to analyze the flow structure in the rotor wheel area. The implemented PSP method of measurement should complete the missing information concerning the pressure distribution on the rotor wheel blades.

\section{Acknowledgements}

The research project "Pressure field visualisation on the surface of the rotor wheel blades of a low-speed compressor stage by means of the PSP method", 5162/B/T02/2011/40, was financed from the funds of the Polish National Science Centre

\section{References}

Gregory, J. W., Asai, K., Kameda, M., Liu, T., \& Sullivan, J. P. (2008). A review of pressure sensitive paint for high-speed and unsteady aerodynamics. Proc. ImechE, Part G: J.Aerospace Engineering, 222, $249-290$. http://dx.doi.org/10.1243/09544100JAERO243

James, H. B. (2004). Applications of Pressure-Sensitive Paint to Testing at Very Low Flow Speeds. 42nd AIAA Aerospace Sciences Meeting and Exhibition, Reno, Nevada.

Liu, T., Guille, M., \& Sullivan, J. P. (2001). Accuracy of Pressure Sensitive Paint. AIAA Journal, $39(1), 103-112$. http://dx.doi.org/10.2514/2.1276

Sakaue, H., Sullivan, J. P., Egami, Y., \& Iijima, Y., et al. (2001). Open-system pressure sensitive paint for surface pressure measurements in a cryogenic wind tunnel, Instrumentation in Aerospace Simulation Facilities, 19th International Congress on ICIASF, 186-195. http://dx.doi.org/10.1109/ICIASF.2001.960250

The Research Project. (2011). Pressure field visualisation on the surface of the rotor wheel blades of a low-speed compressor stage by means of the PSP method, Contract 5162/B/T02/2011/40, financed from the funds of the Polish National Science Centre.

Witkowski, A., Chmielniak, T. J., Strozik, M. D., Majkut, M. M., \& Żukowski, J. M. (2004). Comprehensive Experimental and Computational Investigations of the Unsteady Flow in an Axial Flow Low Speed Compressor Stage, 21st International Congress of Theoretical and Applied Mechanics, Warsaw. Retrieved from http://fluid.ippt.gov.pl/ictam04/CD_ICTAM04/FM10/11916/FM10_11916.pdf

Witkowski, A., Chmielniak, T., Majkut, M., \& Strozik, M. (2003). Measurement of the Unsteady Flow Field Due to Inlet Guide Vane Interaction with the Rotor in an Axial Flow Low Speed Compressor Stage. 5th European Conference on Turbomachinery, Fluid Dynamics and Thermodynamics. Prague, 267-278. Retrieved from http://ame.meil.pw.edu.pl/index.php?/eng/content/download/68/298/file/abs_2006_1_02.pdf

Witkowski, A., Chmielniak, T., \& Strozik, M. (1996). Experimental Study of a 3D Wake Decay and Secondary Flows Behind a Rotor Blade Row of a Low Speed Compressor Stage, ASME 96-GT-415, 1-12.

Witkowski, A., Chmielniak, T., Strozik, M., Majkut, M., \& Żukowski, J. (2005). Experimental and Computational Investigations of the Unsteady Flow in an Axial Flow Low Speed Compressor Stage. 6th European Conference on Turbomachinery Fluid Dynamics and Thermodynamics, Lille, France, 168-177.

Witkowski, A., Ziach, M., Majkut, M., \& Strozik, M. (2008). Experimental investigations of the flow phenomena in the rotor blades of the axial flow low speed compressor stage at the unstable part of the overall performance characteristic, The Archive of Mechanical Engineering, 4, Warszawa, Retrieved from http://ame.meil.pw.edu.pl/index.php?/eng/content/download/324/1518/file/art_2008_4_05.pdf

\section{Copyrights}

Copyright for this article is retained by the author(s), with first publication rights granted to the journal.

This is an open-access article distributed under the terms and conditions of the Creative Commons Attribution license (http://creativecommons.org/licenses/by/3.0/). 